\title{
Brain permeable AMPK activator R481 raises glycemia by autonomic nervous system activation and amplifies the counterregulatory response to hypoglycemia in rats
}

Running Title: R481 amplifies the glucagon response to hypoglycemia in rats.

Ana M. Cruz ${ }^{1}$, Yasaman Malekizadeh ${ }^{1 *}$, Julia M. Vlachaki Walker ${ }^{1 * \$}$, Paul G. Weightman Potter $^{1}$, Katherine Pye ${ }^{1}$, Simon J. Shaw ${ }^{2}$, Kate L.J. Ellacott ${ }^{1}$, Craig Beall ${ }^{1}$. *Contributed equally

${ }^{1}$ Institute of Biomedical and Clinical Sciences, College of Medicine and Health, RILD Building, Barrack Road, Exeter, EX2 5DW

${ }^{2}$ Rigel Pharmaceuticals Inc., 1180 Veterans Boulevard, South San Francisco, CA, 94080, USA

\$Current address: MRC London Institute of Medical Sciences, Imperial College London, Hammersmith Hospital Campus, Clinical Research Building, DuCane road, London W12 ONN

\section{Corresponding Author:}

Craig Beall

Institute of Biomedical and Clinical Sciences, University of Exeter Medical School, RILD Building, Barrack Road, Exeter, EX2 5DW

Tel: +44 (0)1392 408209

Email: c.beall@exeter.ac.uk

Word Count: 3898

Figures: 4 (+ 3 supplemental figures)

Conflict of Interest: Simon J Shaw is an employee and shareholder of Rigel Pharmaceuticals, Inc. All other authors declare that no conflicts of interest. 


\section{ABSTRACT}

AMP-activated protein kinase (AMPK) is a critical cellular and whole body energy sensor activated by energy stress, including hypoglycemia, which is frequently experienced by people with diabetes. Previous studies using direct delivery of an AMPK activator to the ventromedial hypothalamus $(\mathrm{VMH})$ in rodents increased hepatic glucose production. Moreover, recurrent glucoprivation in the hypothalamus leads to blunted AMPK activation and defective hormonal responses to subsequent hypoglycemia. These data suggest that amplifying AMPK activation may prevent or reduce frequency hypoglycemia in diabetes. We used a novel brain-permeable AMPK activator, R481, which potently increased AMPK phosphorylation in vitro. R481 significantly increased peak glucose levels during glucose tolerance tests in rats, which were attenuated by treatment with AMPK inhibitor SBI-0206965 and completely abolished by blockade of the autonomic nervous system. This occurred without altering insulin sensitivity measured by hyperinsulinemic-euglycemic clamps. Endogenous insulin secretion was not altered by R481 treatment. During hyperinsulinemichypoglycemic clamp studies, R481 treatment reduced exogenous glucose requirements and amplified peak glucagon levels during hypoglycemia. These data demonstrate that peripheral administration of the brain permeable AMPK activator R481 amplifies the counterregulatory response to hypoglycemia in rats, which could have clinical relevance for prevention of hypoglycemia. 


\section{INTRODUCTION}

Achieving more time in target blood glucose (BG) range is a daily challenge for people with diabetes. This can become increasingly challenging with tightening glycemic control using insulin treatment, which increases the risk of hypoglycemia. Moreover, disease progression and frequent exposure to hypoglycemia can lead to impaired awareness of and defective counterregulatory responses (CRR) to hypoglycemia (1).

AMP-activated protein kinase (AMPK) has emerged as a central component of cellular energy sensing over the past two decades. The enzyme is a heterotrimeric complex composed of $\alpha, \beta$ and $\gamma$-subunits, with the $\alpha$-subunit containing the catalytic domain (2). There are two isoforms of the $\alpha$-subunit, AMPK $\alpha 1$ and AMPK $\alpha 2$, with the latter isoform having a more prominent role in glucose sensing (3-5). This enzyme plays an important role in regulating whole body energy homeostasis through its actions in the hypothalamus (6) and pancreas $(7,8)$. Previous studies have shown that direct pharmacological activation of AMPK in the ventromedial nucleus of the hypothalamus (VMH), an important hypoglycemiasensing region (9), increases the response to hypoglycemia in normal (10), recurrently hypoglycemic and diabetic BB rats (11) by increasing hepatic glucose production with or without concomitant increases in glucagon and epinephrine levels. Moreover, suppression of AMPK activity using shRNA diminishes the glucagon and epinephrine response to hypoglycemia (12). Recurrent glucoprivation in rats leads to diminished AMPK activation in hypothalamic nuclei during hypoglycemia (13), suggesting that at least in part, recurrent hypoglycemia $(\mathrm{RH})$ may lead to defective CRR through suppression of AMPK activity in the hypothalamus. Importantly, previous studies have thus far only used direct injection of AMPK activators into the brain (10), which is not a viable therapeutic option for humans. Rigel Pharmaceuticals (CA, USA) has developed novel AMPK activating compounds with a similar mechanism of action to metformin (complex I inhibition) (14) but with greater potency). One novel compound, R481, exhibits CNS-permeability and has a positive brain:plasma 
bioRxiv preprint doi: https://doi.org/10.1101/749929; this version posted August 29, 2019. The copyright holder for this preprint (which was not certified by peer review) is the author/funder, who has granted bioRxiv a license to display the preprint in perpetuity. It is made available under aCC-BY-NC-ND 4.0 International license.

distribution. We used this unique compound to test the hypothesis that peripheral delivery of a brain-permeable AMPK activator may improve the CRR to hypoglycemia. 


\section{RESULTS AND DISCUSSION}

R481 potently activates AMPK signalling in vitro. To confirm that R481 activated AMPK in neuronal cells, we utilised the mouse hypothalamic glucose-sensing GT1-7 cells (3). Treatment for 30 minutes with increasing concentrations of R481 increased phosphorylation of AMPK at threonine 172 (a site required for full kinase activation) that was statistically significant at concentrations $>10 \mathrm{nmol} / \mathrm{L}$ (Fig. 1A,B). Phosphorylation of the downstream AMPK substrate, ACC, was also significantly elevated by R481 (Fig. 1A,C). Despite AMPK activation, total intracellular ATP levels were not compromised by R481, even at concentrations up to $200 \mathrm{nmol} / \mathrm{L}$ (Fig. 1D). Using extracellular flux analysis, we confirmed mild mitochondrial inhibition, in the form of reduced oxygen consumption rate (OCR) in the mouse pancreatic aTC1-9 cell line (Supp Fig. 1). These data suggest that R481 potently and rapidly increases AMPK activity. This contrasts with metformin, which has weak brain permeability and requires transport through organic cation transporter 1 (OCT1), taking several hours to mildly inhibit mitochondria in cells $(15,16)$.

R481 enters the brain but does not alter ad libitum, fasting or hypoglycemia induced feeding. Dosing studies in mice demonstrated that R481 rapidly enters the brain (Supp Fig.2A), displays a brain:plasma ratio of $>3$ (Supp Fig. 2B) and increases whole brain AMPK phosphorylation following bolus intravenous infusion in mice (Supp Fig. 2C). In contrast, R419 did not display significant brain permeability. As hypothalamic AMPK increases feeding (6) and leptin-induced repression of feeding requires inhibition of AMPK (17), we postulated that a brain permeable AMPK activator may increase feeding behaviour. However, R481 failed to alter ad libitum, fasting or hypoglycemia-induced feeding in rats (Supp Fig. 3). 
R481 raises peak glycemia which is attenuated by AMPK inhibitor SBI-0206965 and abolished by autonomic blockade. To determine whether R481 altered glucose tolerance, rats were treated with R481 (5-20 $\mathrm{mg} \mathrm{kg}^{-1}$ ) simultaneously with intraperitoneal glucose. R481 significantly increased the peak glucose excursion yet glucose levels were not significantly different between groups at 2 hours, suggesting effective clearance of glucose. This transient increase in peak glucose levels was attenuated by pre-treatment with AMPK/Uncoordinated (Unc)-51-like kinase (ULK-1) inhibitor SBI-0206965 (3 mg kg ${ }^{-1}$; Fig. 2A), which inhibits AMPK in vitro at nanomolar concentrations (18). Previous studies have shown that suppression or activation of hypothalamic AMPK activity can attenuate or stimulate hepatic glucose production, respectively (19-21), indicating that hypothalamic AMPK activity regulates hepatic glucose production (HGP). Our data concur with these observations as R481 (delivered peripherally) increased glycaemia, an effect attenuated by AMPK inhibition.

The study by Kume and colleagues (22) demonstrated that activation of hypothalamic AMPK suppresses first phase glucose-stimulated insulin secretion (GSIS) through autonomic innervation of a-adrenergic pancreatic nerves. This is suggested to be a physiological response to promote glucose delivery to the brain during fasting (22), a mechanism that may also occur during hypoglycemia. Given the large and transient increase in peak glucose, coinciding with predicted first-phase insulin secretion, we pre-treated rats with pan autonomic blocker hexamethonium $\left(50 \mathrm{mg} \mathrm{kg}^{-1}\right)$ for 30 minutes prior to glucose tolerance testing. This drug completely abolished the effect of R481 to alter glucose tolerance (Fig. 2B). Furthermore, the R481 effect was not reproduced following treatment with non-brain permeable R419 (Fig 2B), further supporting a central action of R481 in regulating glycemia. 
R481 does not alter glucose infusion rates during euglycemic clamping. We examined whether acute R481 administration one hour prior to a hyperinsulinemic-euglycemic clamp (blood glucose target: $5.5 \mathrm{mmol} / \mathrm{L}$ ) would alter glucose infusion rates. R481 (20 $\mathrm{mg} \mathrm{kg}^{-1}$ ) or vehicle, was administered intraperitoneally 60 minutes before insulin infusion (see study design, Fig. 3A). Baseline glucose levels were slightly increased in $\mathrm{R} 481$ treated animals $(\mathrm{t}=$ $-60 \mathrm{mins} ; 7.2 \pm 0.2 \mathrm{mmol} / \mathrm{L}$ vs $\mathrm{t}=07.5 \pm 0.2 \mathrm{mmol} / \mathrm{L})$, whereas in vehicle treated animals, BG levels decreased ( $\mathrm{t}=-60$ mins $7.1 \pm 0.6$ to $\mathrm{t}=0 ; 6.3 \pm 0.2 \mathrm{mmol} / \mathrm{L})$. This produced $\mathrm{a}$ significant relative increase in $B G$ at the start of the clamp in $R 481$ treated animals $(P<0.05$; $\mathrm{n}=8$; Fig. 3B). Glucose levels were well matched during the last 30 minutes of the clamp (Fig. 3B), with no difference in the glucose infusion rate (GIR; Fig. 3C). Contrary to our expectations, R481 had no effect on C-peptide levels (Fig. 3D) suggesting that basal endogenous insulin secretion was not altered. This suggests that the augmented peak glucose levels during the GTT are unlikely to be mediated by suppression of endogenous insulin secretion.

AMPK activators have been developed for glucose lowering in Type 2 Diabetes, largely by acting on skeletal muscle to promote glucose disposal $(23,24)$. Moreover, the R481 analogue, R419 (non-brain permeable) activates AMPK in skeletal muscle and increases insulin sensitivity in high-fat fed mice (25). We postulated that R481 treatment may increase the GIR during the euglycemic clamp by enhancing skeletal muscle glucose uptake. However, we have no evidence of altered glucose disposal or insulin sensitivity. In our study, we examined glucose homeostasis following a single injection of the drug in lean rats, rather than chronic dosing in high fat fed mice (25), which may explain the discrepancy. However, these data suggest that the transient glucose intolerance in the GTT study was not mediated by a change to insulin sensitivity. Using glucose tracers to determine the rates of glucose appearance and disappearance will be important going forward to closely examine HGP and skeletal muscle glucose uptake. 
$R 481$ reduces the GIR and increases glucagon levels during hypoglycemia. To expose the potential influence of central AMPK activation using R481 on CRR, we maintained rats at hypoglycaemia $(2.8 \mathrm{mmol} / \mathrm{L})$ during a 90 minute clamp study (Study design Fig. 4A). Glucose levels during the clamp were well matched between vehicle and R481-treated rats (Fig. 4B). Exogenous glucose infusion required to maintain hypoglycemia was significantly lower in R481-treated animals compared to vehicle (Fig. 4C). Plasma glucagon levels were significantly higher in the R481 treated group (Fig. 4D,E). Epinephrine levels were not modified by $R 481$ and were undetectable 60 minutes after $R 481$ injection ( $t=0$; Fig. 4F,G), indicating that R481 does not alter catecholamine secretion directly. Importantly, baseline glucagon levels (during euglycemia; $t=0$ ) were not altered, suggesting that increased glucagon levels are not likely to be driving the glucose intolerance in the GTTs.

In previous studies with non-diabetic rats, direct pharmacological activation of AMPK in the VMH using AICAR, amplified HGP during hypoglycemia, without altering CRR hormones (10). In pancreatic $\alpha$-cells, pharmacological and genetic activation of AMPK is sufficient to stimulate glucagon release (8). In our study, it is plausible that R481 activates an AMPKANS-HGP axis whilst also augmenting glucagon secretion via $\alpha$-cell AMPK directly. In streptozotocin-induced diabetic rats however, VMH AICAR injection can augment both glucagon and epinephrine responses during hypoglycemia (11). Given that hyperglycemia and recurrent hypoglycemia/glucoprivation suppress hypothalamic AMPK activity $(6,13)$ and that direct genetic suppression of VMH AMPK expression/activity suppresses glucagon and epinephrine responses to hypoglycemia (12) it is plausible that hypothalamic AMPK activity is blunted in diabetes, leading, at least in part, to defective CRR.

We demonstrate that R481 raised peak glucose levels during GTTs, without negatively impacting glucose clearance in a manner that was attenuated by AMPK inhibition and 
completely abolished by autonomic blockade, suggesting R481 acts centrally. Moreover, R481 did not alter C-peptide levels, suggesting that R481 does not suppress insulin secretion and likely increases glycemia by stimulating HGP, as has been previously reported following viral and pharmacological manipulation of hypothalamic AMPK activity (19-21). We also show that during hypoglycemia glucagon levels were amplified by R481. This effect could be mediated by direct activation of AMPK within the $\alpha$-cell as pharmacological and genetic activation of $\alpha$-cell AMPK stimulates glucagon secretion $(7,8)$. Importantly, this indicates that the likely net effect of AMPK activation throughout the whole body is to increase glucose delivery to the brain, as previously suggested (22), indicating that at the level of the whole organism, central AMPK activation may supersede peripheral activation in a hierarchical manner, akin to that suggested for subcellular pools of AMPK (26).

In summary, our data indicate that peripheral delivery of a brain permeable AMPK activator raises glycemia, likely to protect brain function by providing more substrate for brain cell metabolism. We provide proof-of-concept that pharmacological activation of AMPK may be a suitable therapeutic target for amplifying the defence against hypoglycemia. This requires testing in rodent models of type 1 and type 2 diabetes and in rodents with defective CRR and optimisation of the dose to amplify CRR without worsening fasting/fed hyperglycemia. Development of brain permeable allosteric activators of AMPK could be useful for prevention of hypoglycemia in diabetes. 


\section{METHODS}

\section{Cell culture}

Immortalised GT1-7 mouse hypothalamic cells were a kind gift from Pamela Mellon, Salk Institute, San Diego, California, USA. See supplementary methods for culture details. For experimentation, cells were incubated in serum-free DMEM containing physiologic brain glucose levels $(2.5 \mathrm{mmol} / \mathrm{L}$ glucose). Cell lines were confirmed as mycoplasma free using a commercial kit (MycoAlert, Lonza, Slough, UK).

\section{Immunoblotting}

Cells were grown to $60-70 \%$ confluence in $60 \mathrm{~mm}$ round petri dishes. Following treatment, cells lysates were collected for protein quantification using the Bradford method (27), separated using SDS-PAGE and transferred to nitrocellulose membrane. Total and phosphorylated protein was detected and semi-quantified using infrared fluorescence on the Licor Odyssey scanner. See supplemental methods for antibody details.

\section{Analysis of cellular metabolism}

Mitochondrial oxygen consumption rates $(\mathrm{OCR})$ were measured using the $\mathrm{XF}^{\mathrm{e}} 96$ Agilent Seahorse Extracellular Flux analyzer, as previously described (28). See supplemental methods for additional details.

\section{Determination of ATP concentrations}

Cells were grown in 96-well plates overnight and intracellular ATP concentrations were measured using the ATPlite two-step assay (PerkinElmer, UK) as per manufacturer's instructions and as previously described (28). 


\section{Animals}

Male Sprague-Dawley rats (250-350 g, Charles River Laboratories, Margate, Kent, UK) were maintained on a 12 -hour light cycle, temperature $22-23 \stackrel{\circ}{\circ}, 55 \%$ humidity and provided with food (Lab Diet; catalogue number 5LF2) and water ad libitum.

\section{Glucose tolerance tests}

Male Sprague Dawley rats were fasted overnight. For studies using SBI-0206965 (3 mg kg ${ }^{-1}$; i.p.) and hexamethonium (50 $\mathrm{mg} \mathrm{kg}^{-1}$; i.p.), either drug was delivered 30 minutes before glucose (2 $\mathrm{g} \mathrm{kg}^{-1}$; i.p.) +/- R481 (5-20 mg kg-1; i.p); R419 (20 $\left.\mathrm{mg} \mathrm{kg}^{-1}\right)$ or vehicle $(0.5 \%$ HPMC + $0.1 \%$ TWEEN-80) in a single injection. Blood glucose measured at 0, 15, 30, 60 and 120 minutes from a tail vein prick by handheld glucometer (AccuCheck, Roche).

\section{Hyperinsulinemic clamp studies}

Male Sprague-Dawley rats with pre-implanted jugular vein and carotid artery catheters were purchased from Charles River (Margate, UK). Rats were fasted overnight (16 hours). R481 (20 mg kg-1 ; i.p.; Rigel Pharmaceuticals) or vehicle (0.5\% HPMC, 0.1\% TWEEN-80 prepared in distilled sterile $\mathrm{H}_{2} \mathrm{O}$ ) was administered one hour prior to the hyperinsulinemic-euglycemic or hypoglycemic clamp. Blood glucose was measured every 5-10 min and larger blood samples for hormone analysis were collected every $30 \mathrm{~min}$.

\section{Hormone and metabolite analysis}


Plasma glucagon and C-peptide were measured using the Mercodia Glucagon and Cpeptide ELISA kits (Uppsala, Sweden). Plasma epinephrine was measured using the Demeditec Adrenaline ELISA (Kiel, Germany).

\section{Statistical analysis}

A one-sample t-test was used to determine significant changes in phosphorylation or total protein expression relative to control in immunoblotting experiments. Plasma glucose levels, glucose infusion rates and plasma analytes were analysed using a two-way ANOVA with repeated measures. Peak hormone levels were analysed using an unpaired t-test. Analysis was performed using the GraphPad Prism software (Prism 8, GraphPad Software, La Jolla, CA, USA). Results are expressed as mean \pm SEM, with $p<0.05$ considered statistically significant.

\section{Study approval}

All procedures were approved by the University of Exeter Animal Welfare and Ethical Review body and were performed in accordance to the Animals Scientific Procedures Act (1986). 
bioRxiv preprint doi: https://doi.org/10.1101/749929; this version posted August 29, 2019. The copyright holder for this preprint (which was not certified by peer review) is the author/funder, who has granted bioRxiv a license to display the preprint in perpetuity. It is made available under aCC-BY-NC-ND 4.0 International license.

\section{AUTHOR CONTRIBUTIONS}

A.M.C, Y.M., J.M.V.W., P.G.W.P, K.P, and C.B. researched data. A.M.C., J.M.V.W., S.S., K.L.J.E., and C.B., contributed to study design. All authors contributed to writing the manuscript and approved the final version. C.B. conceived the study, had access to all the data collected at the University of Exeter and takes responsibility for the accuracy and integrity of the data. 


\section{ACKNOWLEDGEMENTS}

This study was funded by: a JDRF Innovative grant (1-INO-2016-214-A-N) to C.B. and K.L.J.E; a Diabetes UK RD Lawrence Fellowship to C.B. (13/0004647); a Society for Endocrinology early career grant to C.B. and a British Society for Neuroendocrinology practical skills grant to C.B. A.M.C. is funded by a University of Exeter Medical School PhD studentship. We wish to thank Jennifer Gallagher, Dr Alison McNeilly, Prof Rory McCrimmon and Gary Park. We also wish to thank Prof René Remie for surgical refinements. 


\section{FIGURE LEGENDS}

Figure 1. AMPK is activated in GT1-7 hypothalamic neuronal cells in response to R481.

Mouse GT1-7 hypothalamic neurons treated with increasing concentrations of R481 for 30 minutes. R481 treatment resulted in a concentration-dependent increase in AMPK (pT172) and ACC (pS79) phosphorylation. A. Representative Western blots for AMPK (pT172), total AMPK, ACC (pS79), total ACC and Actin. Densitometric analysis of the mean pooled data for phospho-AMPK normalised to total AMPK shown in B $(n=6)$ and phospho-ACC normalised to total ACC in $\mathbf{C}(\mathrm{n}=8)\left({ }^{* *} \mathrm{P}<0.01 ;{ }^{* *} \mathrm{P}<0.001\right.$; One-sample t-test in comparison to control). D. Intracellular ATP levels of GT1-7 cells treated with R481, normalised to vehicle (30 mins; 0-200 $\mathrm{nmol} / \mathrm{L} ; \mathrm{n}=6)$.

Figure 2. R481 induced increase in peak glycemia is attenuated by AMPK inhibitor SBI-0206965 and ANS blocker hexamethonium.

Glucose tolerance tests in male Sprague-Dawley rats. A. After $16 \mathrm{hr}$ fast, rats were administered SBI-0206965 (3 $\mathrm{mg} \mathrm{kg}^{-1}$; i.p.) or vehicle for 30 minutes before R481 (5 mg kg 1; i.p.) or vehicle (HPMC/Tween-80; i.p.) treatment together with glucose $\left(2 \mathrm{~g} \mathrm{~kg}^{-1}\right.$; i.p.). Blood glucose was measured immediately prior to $\mathrm{R} 481$ treatment $(t=0)$ and after $15,30,60$ and 120 minutes from the tail vein (SBI-0206965 $n=6$; R481 $n=10 ; R 481+$ SBI-0206965 n=8); Two-way ANOVA with repeated measures ${ }^{*} \mathrm{P}<0.05$ (drug), $\quad{ }^{* * *} \mathrm{P}<0.001$ (time), ${ }^{* * *} \mathrm{P}<0.001$ (interaction) and Bonferonni's multiple comparisons analysis, $\quad{ }^{* *} \mathrm{P}<0.01$, ${ }^{* * *} \mathrm{P}<0.001$ for $\mathrm{R} 481$ against vehicle, ${ }^{\$} \mathrm{P}<0.05$ for $\mathrm{R} 481$ versus $\mathrm{R} 481+\mathrm{SBI}-0206965$. B. After a $16 \mathrm{hr}$ fast, rats were given an glucose load $\left(2 \mathrm{~g} \mathrm{~kg}^{-1}\right.$; i.p.) alongside one of five drug treatments: vehicle (HPMC/Tween-80; $\mathrm{n}=6$ ), vehicle with hexamethonium (50 mg kg-1) $($ Veh+Hex, $\mathrm{n}=3), \quad \mathrm{R} 419\left(20 \mathrm{mg} \mathrm{kg}{ }^{-1}\right)(\mathrm{n}=6), \mathrm{R} 481\left(20 \mathrm{~m} \mathrm{~kg}^{-1}\right)(\mathrm{n}=6)$ or R481 with hexamethonium (R481+Hex, $n=4)$; and blood glucose measured through tail vein samples 15, 30, 60 and 120 minutes after injection. Two-way ANOVA with repeated measures, 
${ }^{* *} \mathrm{P}<0.01$ (drug), $\quad{ }^{* *} \mathrm{P}<0.001$ (time), $\quad{ }^{* * *} \mathrm{P}<0.001$ (interaction), with Bonferonni's analysis ${ }^{* *} \mathrm{P}<0.01,{ }^{* * *} \mathrm{P}<0.001$ for $\mathrm{R} 481$ against vehicle; ${ }^{\$ \$} \mathrm{P}<0.01,{ }^{\$ \$ \$} \mathrm{P}<0.001$ for $\mathrm{R} 481$ against $\mathrm{R} 481+\mathrm{Hex}$.

Figure 3. R481 does not alter glucose infusion rate during hyperinsulinemiceuglycemic clamp or alter endogenous insulin secretion

Hyperinsulinemic-euglycemic clamps performed in male Sprague-Dawley rats. A. Study design. B. Blood glucose profiles (Vehicle $n=8, R 481 \mathrm{n}=8 ; 20 \mathrm{mg} \mathrm{kg}^{-1}$; i.p.). No overall drug effects $P>0.05$ (drug); mixed-effects analysis of repeated measures, but ${ }^{*} P<0.05$ for $R 481$ against vehicle at $\mathrm{t}=0$ mins, using Bonferroni's post-hoc test. C. Glucose infusion rate (GIR; $\mathrm{mg} \mathrm{kg}^{-1} \mathrm{~min}-1$ ) during the clamp using a $50 \%$ dextrose solution (Vehicle $\mathrm{n}=8 ; \mathrm{R} 481 \mathrm{n}=8$ ). D. Plasma C-peptide measured by ELISA (Vehicle $n=8 ; R 481 n=7$ ).

Figure 4. R481 delays exogenous glucose requirements during hyperinsulinemichypoglycemic clamp by augmenting glucagon levels during hypoglycemia

Hyperinsulinemic-hypoglycemic clamps performed in male Sprague-Dawley rats. A. Study design. Animals were fasted for 16 hrs. R481 (20 mg kg-1; i.p.) or vehicle (HPMC/Tween-80; i.p.) were administered 60 minutes before the start of the clamp. Blood glucose was measured every 10 minutes and samples collected for plasma analysis at 30 minute intervals. B. Blood glucose profiles before and during clamp (Vehicle $n=10 ; R 481 n=8$ ). C. Glucose infusion rates (GIR; $\mathrm{mg} \mathrm{kg}^{-1} \mathrm{~min}^{-1}$ ) during the clamp using a $20 \%$ dextrose solution. ${ }^{*} \mathrm{P}($ drug $)<0.05, \quad{ }^{* *} \mathrm{P}($ time $)<0.05, \quad{ }^{*} \mathrm{P}($ interaction $)<0.05$; two-way ANOVA with repeated measures. D. Plasma glucagon profile with peak shown in E, measured by ELISA (Vehicle $n=9$; R491 $n=9$; * $P<0.05$, unpaired t-test). F. Plasma epinephrine profile with peak shown in G, meaured by ELISA (Vehicle $n=8 ; R 481 n=8 ; n s$, not significant). 


\section{REFERENCES}

1. Segel SA, Paramore DS, Cryer PE. Hypoglycemia-associated autonomic failure in advanced type 2 diabetes. Diabetes. 2002;51(3):724-733.

2. Carling D, Clarke PR, Zammit VA, Hardie DG. Purification and characterization of the AMPactivated protein kinase. Copurification of acetyl-CoA carboxylase kinase and 3-hydroxy-3methylglutaryl-CoA reductase kinase activities. Eur J Biochem. 1989;186(1-2):129-136.

3. Beall C, Hamilton DL, Gallagher J, et al. Mouse hypothalamic GT1-7 cells demonstrate AMPKdependent intrinsic glucose-sensing behaviour. Diabetologia. 2012;55(9):2432-2444.

4. Sun G, Tarasov Al, McGinty J, et al. Ablation of AMP-activated protein kinase alpha 1 and alpha 2 from mouse pancreatic beta cells and RIP2.Cre neurons suppresses insulin release in vivo. Diabetologia. 2010;53(5):924-936.

5. Beall C, Piipari K, Al-Qassab H, et al. Loss of AMP-activated protein kinase alpha 2 subunit in mouse beta-cells impairs glucose-stimulated insulin secretion and inhibits their sensitivity to hypoglycaemia. Biochemical Journal. 2010;429:323-333.

6. Minokoshi $\mathrm{Y}$, Alquier T, Furukawa N, et al. AMP-kinase regulates food intake by responding to hormonal and nutrient signals in the hypothalamus. Nature. 2004;428(6982):569-574.

7. Sun G, da Silva Xavier G, Gorman T, et al. LKB1 and AMPKalpha1 are required in pancreatic alpha cells for the normal regulation of glucagon secretion and responses to hypoglycemia. Mol Metab. 2015;4(4):277-286.

8. Leclerc I, Sun G, Morris C, Fernandez-Millan E, Nyirenda M, Rutter GA. AMP-activated protein kinase regulates glucagon secretion from mouse pancreatic alpha cells. Diabetologia. 2011;54(1):125-134.

9. Borg MA, Sherwin RS, During MJ, Borg WP, Shulman GI. Local Ventromedial Hypothalamus Glucose Perfusion Blocks Counterregulation During Systemic Hypoglycemia. Diabetes. 1995;44:A3-A3.

10. McCrimmon RJ, Fan X, Ding Y, Zhu W, Jacob RJ, Sherwin RS. Potential role for AMP-activated protein kinase in hypoglycemia sensing in the ventromedial hypothalamus. Diabetes. 2004;53(8):1953-1958.

11. Fan X, Ding Y, Brown S, et al. Hypothalamic AMP-activated protein kinase activation with AICAR amplifies counterregulatory responses to hypoglycemia in a rodent model of type 1 diabetes. Am J Physiol Regul Integr Comp Physiol. 2009;296(6):R1702-1708.

12. McCrimmon RJ, Shaw M, Fan X, et al. Key role for AMP-activated protein kinase in the ventromedial hypothalamus in regulating counterregulatory hormone responses to acute hypoglycemia. Diabetes. 2008;57(2):444-450.

13. Alquier T, Kawashima J, Tsuji Y, Kahn BB. Role of hypothalamic adenosine 5 'monophosphate activated protein kinase in the impaired counterregulatory response induced by repetitive neuroglucopenia. Endocrinology. 2007;148(3):1367-1375.

14. Jenkins $Y$, Sun T-Q, Markovtsov V, et al. AMPK Activation through Mitochondrial Regulation Results in Increased Substrate Oxidation and Improved Metabolic Parameters in Models of Diabetes. PLOS ONE. 2013;8(12):e81870.

15. Wang DS, Jonker JW, Kato $\mathrm{Y}$, Kusuhara H, Schinkel AH, Sugiyama Y. Involvement of organic cation transporter 1 in hepatic and intestinal distribution of metformin. The Journal of pharmacology and experimental therapeutics. 2002;302(2):510-515.

16. Logie L, Harthill J, Patel K, et al. Cellular responses to the metal-binding properties of metformin. Diabetes. 2012;61(6):1423-1433.

17. Dagon Y, Hur E, Zheng B, Wellenstein K, Cantley LC, Kahn BB. p70S6 kinase phosphorylates AMPK on serine 491 to mediate leptin's effect on food intake. Cell Metab. 2012;16(1):104112.

18. Dite TA, Langendorf CG, Hoque A, et al. AMP-activated protein kinase selectively inhibited by the type II inhibitor SBI-0206965. Journal of Biological Chemistry. 2018. 
19. Yang CS, Lam CKL, Chari M, et al. Hypothalamic AMP-Activated Protein Kinase Regulates Glucose Production. Diabetes. 2010;59(10):2435-2443.

20. Lam CK, Chari M, Rutter GA, Lam TK. Hypothalamic nutrient sensing activates a forebrainhindbrain neuronal circuit to regulate glucose production in vivo. Diabetes. 2011;60(1):107113.

21. Kinote A, Faria JA, Roman EA, et al. Fructose-induced hypothalamic AMPK activation stimulates hepatic PEPCK and gluconeogenesis due to increased corticosterone levels. Endocrinology. 2012;153(8):3633-3645.

22. Kume S, Kondo M, Maeda S, et al. Hypothalamic AMP-Activated Protein Kinase Regulates Biphasic Insulin Secretion from Pancreatic beta Cells during Fasting and in Type 2 Diabetes. EBioMedicine. 2016;13:168-180.

23. Merrill GF, Kurth EJ, Hardie DG, Winder WW. AICA riboside increases AMP-activated protein kinase, fatty acid oxidation, and glucose uptake in rat muscle. American Journal of Physiology-Endocrinology and Metabolism. 1997;36(6):E1107-E1112.

24. Kurth-Kraczek EJ, Hirshman MF, Goodyear L, Winder WW. 5 ' AMP-activated protein kinase activation causes GLUT4 translocation in skeletal muscle. Diabetes. 1999;48(8):1667-1671.

25. Marcinko K, Bujak AL, Lally JS, et al. The AMPK activator R419 improves exercise capacity and skeletal muscle insulin sensitivity in obese mice. Mol Metab. 2015;4(9):643-651.

26. Zong $\mathrm{Y}$, Zhang C-S, Li M, et al. Hierarchical activation of compartmentalized pools of AMPK depends on severity of nutrient or energy stress. Cell Research. 2019;29(6):460-473.

27. Bradford MM. Rapid and Sensitive Method for Quantitation of Microgram Quantities of Protein Utilizing Principle of Protein-Dye Binding. Analytical Biochemistry. 1976;72(1-2):248254.

28. Vlachaki Walker JM, Robb JL, Cruz AM, et al. AMP-activated protein kinase (AMPK) activator A-769662 increases intracellular calcium and ATP release from astrocytes in an AMPKindependent manner. Diabetes Obes Metab. 2017;19(7):997-1005. 
bioRxiv preprint do: festryed by A eecreview) is the author/funder, who has granted bioRxiv a license to display Repreprint in perpetury. It

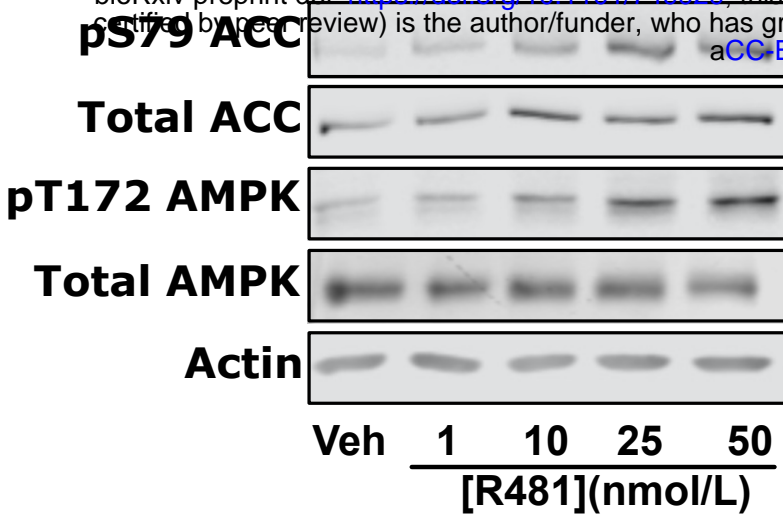

pS79 ACCIACC

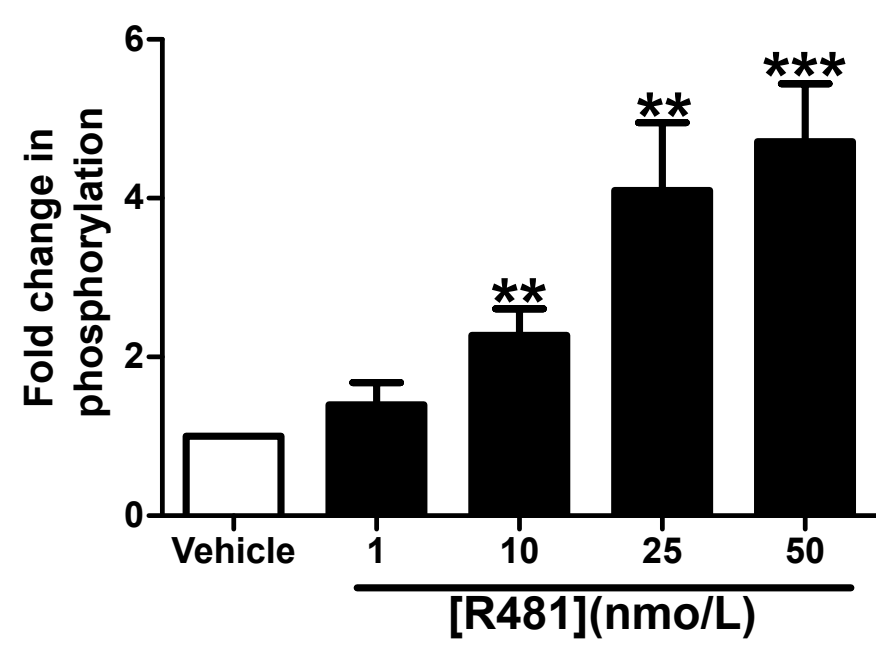

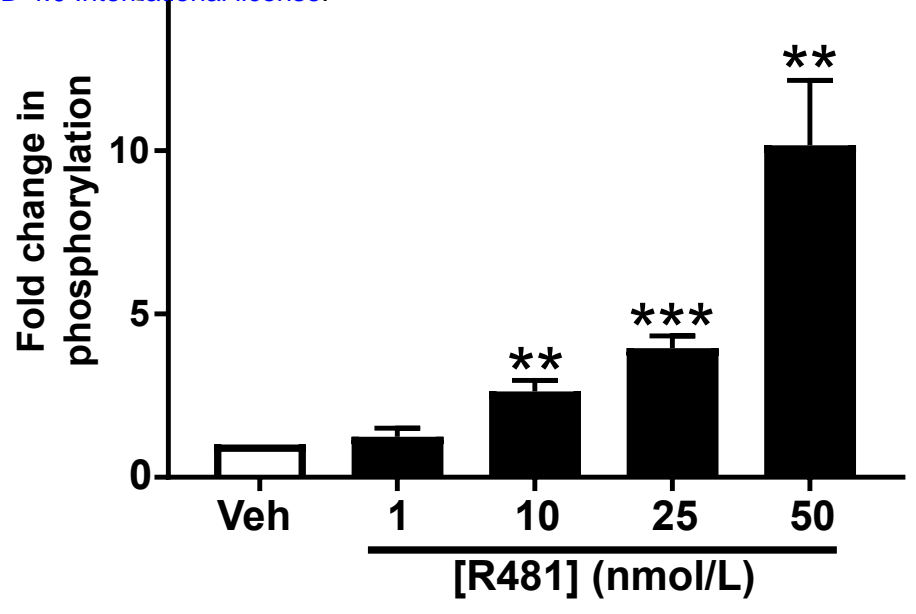

D

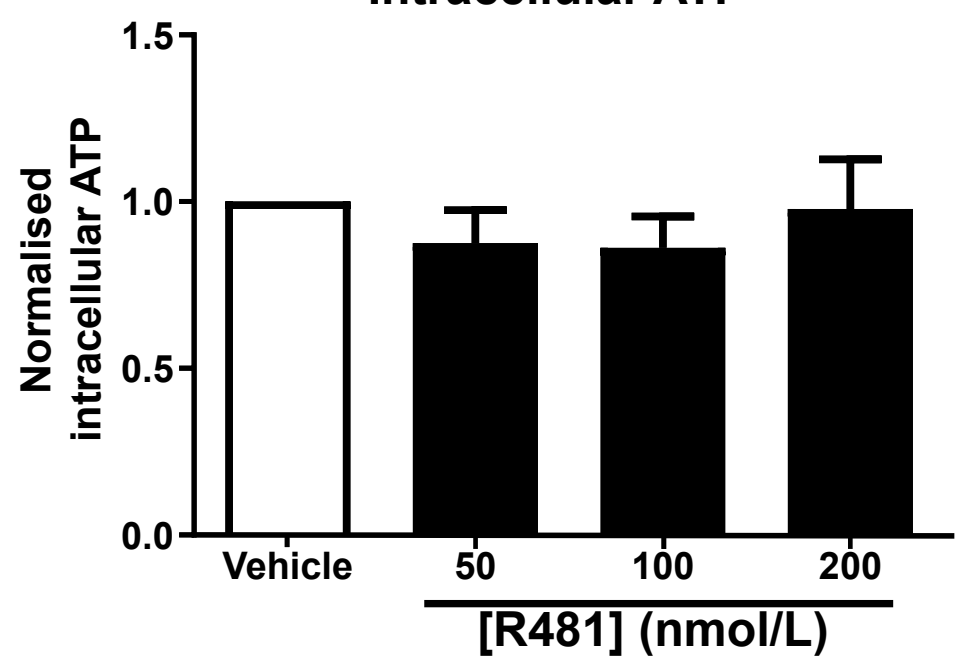

Figure 1. AMPK is activated in GT1-7 hypothalamic neuronal cells in response to R481. Mouse GT1-7 hypothalamic neurons treated with increasing concentrations of R481 for 30 minutes. R481 treatment resulted in a concentration-dependent increase in AMPK (pT172) and ACC (pS79) phosphorylation. A. Representative Western blots for AMPK (pT172), total AMPK, ACC (pS79), total $A C C$ and Actin. Densitometric analysis of the mean pooled data for phospho-AMPK normalised to total AMPK shown in $\mathbf{B}(n=6)$ and phospho-ACC normalised to total ACC in $\mathbf{C}(n=8)\left({ }^{* *} P<0.01\right.$; ${ }^{* * *} \mathrm{P}<0.001$; One-sample t-test in comparison to control). D. Intracellular ATP levels of GT1-7 cells treated with R481, normalised to vehicle (30 mins; 0-200 $\mathrm{nmol} / \mathrm{L} ; \mathrm{n}=6$ ). 
bioRxiv preprint doi: https://doi.org/10.1101/749929; this version posted August 29, 2019. The copyright holder for this preprint (which was not certified by peer review) is the author/funder, who has granted bioRxiv a license to display the preprint in perpetuity. It is made available under aCC-BY-NC-ND 4.0 International license.

A

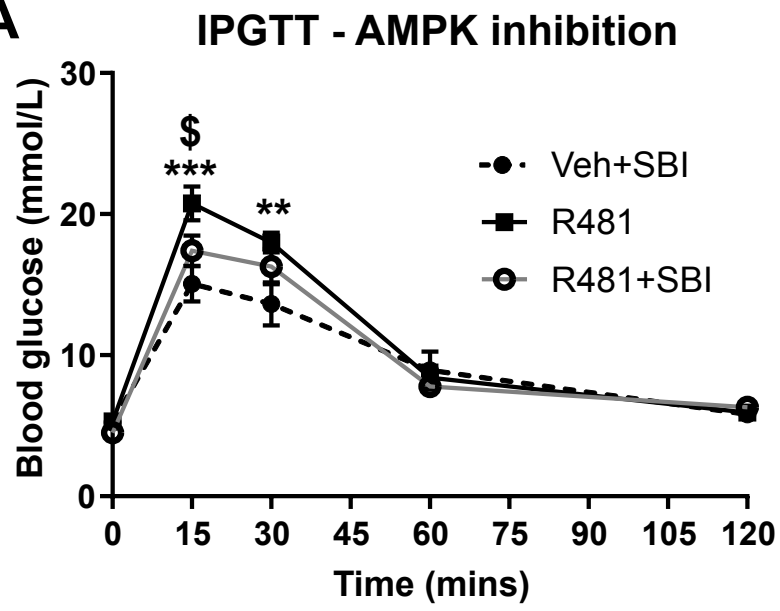

B

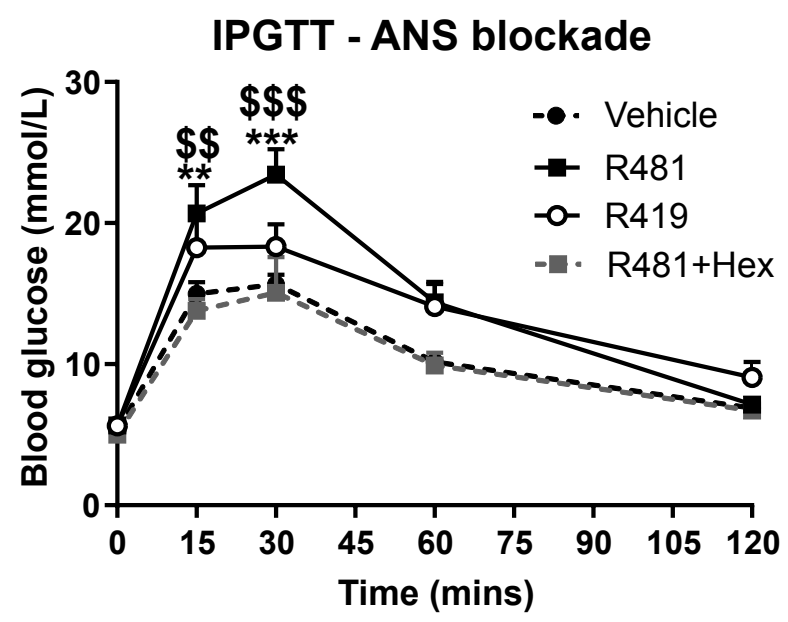

Figure 2. R481 induced increase in peak glycemia is attenuated by AMPK inhibitor SBI-0206965 and ANS blocker hexamethonium.

Glucose tolerance tests in male Sprague-Dawley rats. A. After 16hr fast, rats were administered SBI-0206965 (3 mg $\mathrm{kg}^{-1}$; i.p.) or vehicle for 30 minutes before R481 (5 mg kg-1; i.p.) or vehicle (HPMC/Tween-80; i.p.) treatment together with glucose $\left(2 \mathrm{~g} \mathrm{~kg}^{-1}\right.$; i.p.). Blood glucose was measured immediately prior to $\mathrm{R} 481$ treatment $(\mathrm{t}=0)$ and after 15, 30, 60 and 120 minutes from the tail vein (SBI-0206965 n=6; R481 n=10; R481+SBI-0206965 n=8); Twoway ANOVA with repeated measures ${ }^{*} P<0.05$ (drug), ${ }^{* * *} P<0.001$ (time), ${ }^{* * *} P<0.001$ (interaction) and Bonferonni's multiple comparisons analysis, ${ }^{* *} \mathrm{P}<0.01,{ }^{* * *} \mathrm{P}<0.001$ for $\mathrm{R} 481$ against vehicle, ${ }^{\$} \mathrm{P}<0.05$ for $\mathrm{R} 481$ versus $\mathrm{R} 481$ +SBI-0206965. B. After a $16 \mathrm{hr}$ fast, rats were given an glucose load $\left(2 \mathrm{~g} \mathrm{~kg}^{-1}\right.$; i.p.) alongside one of five drug treatments: vehicle (HPMC/Tween-80; $\mathrm{n}=6)$, vehicle with hexamethonium $\left(50 \mathrm{mg} \mathrm{kg}^{-1}\right)($ Veh+Hex, $\mathrm{n}=3), \mathrm{R} 419(20$ $\left.\mathrm{mg} \mathrm{kg}^{-1}\right)(\mathrm{n}=6)$, R481 $\left(20 \mathrm{~m} \mathrm{~kg}^{-1}\right)(\mathrm{n}=6)$ or R481 with hexamethonium (R481+Hex, $\left.\mathrm{n}=4\right)$; and blood glucose measured through tail vein samples 15, 30, 60 and 120 minutes after injection. Two-way ANOVA with repeated measures, ${ }^{* *} \mathrm{P}<0.01$ (drug), ${ }^{* * *} \mathrm{P}<0.001$ (time), ${ }^{* * *} \mathrm{P}<0.001$ (interaction), with Bonferonni's analysis ${ }^{* *} \mathrm{P}<0.01$, ${ }^{* * *} \mathrm{P}<0.001$ for $R 481$ against vehicle; ${ }^{\$}{ }_{P}<0.01, \$ \$ \$ P<0.001$ for $R 481$ against $R 481+$ Hex. 


$$
\begin{aligned}
& \text { Blood glucose + sample } \\
\longrightarrow & \text { R481/Vehicle i.p. } \\
\longrightarrow \text { Insulin }(80 \mathrm{mU} \mathrm{Kg} & \mathrm{min}^{-1} \text { ) }
\end{aligned}
$$

bioRxiv preprint doi: https://doi.org/10.110 certified by peer review) is the author/funder, who has granted bioRxiv a licentuity. It is made available under

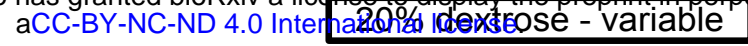

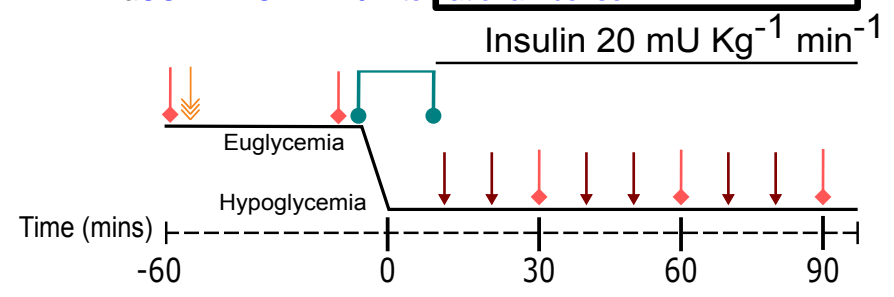

B

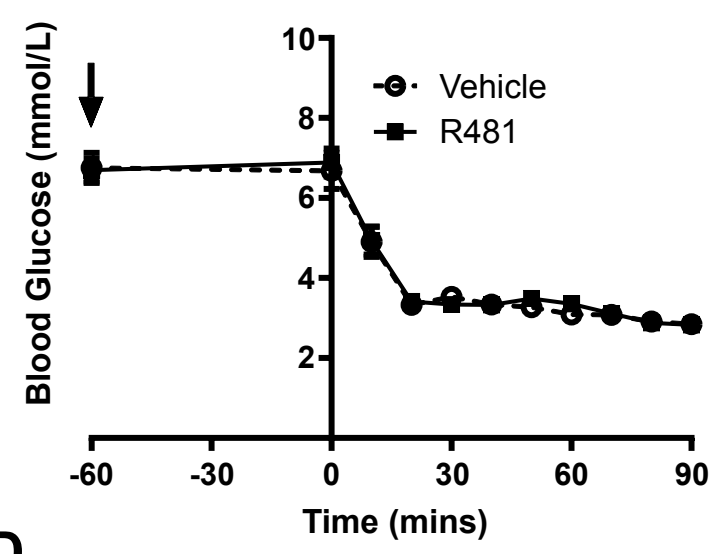

D
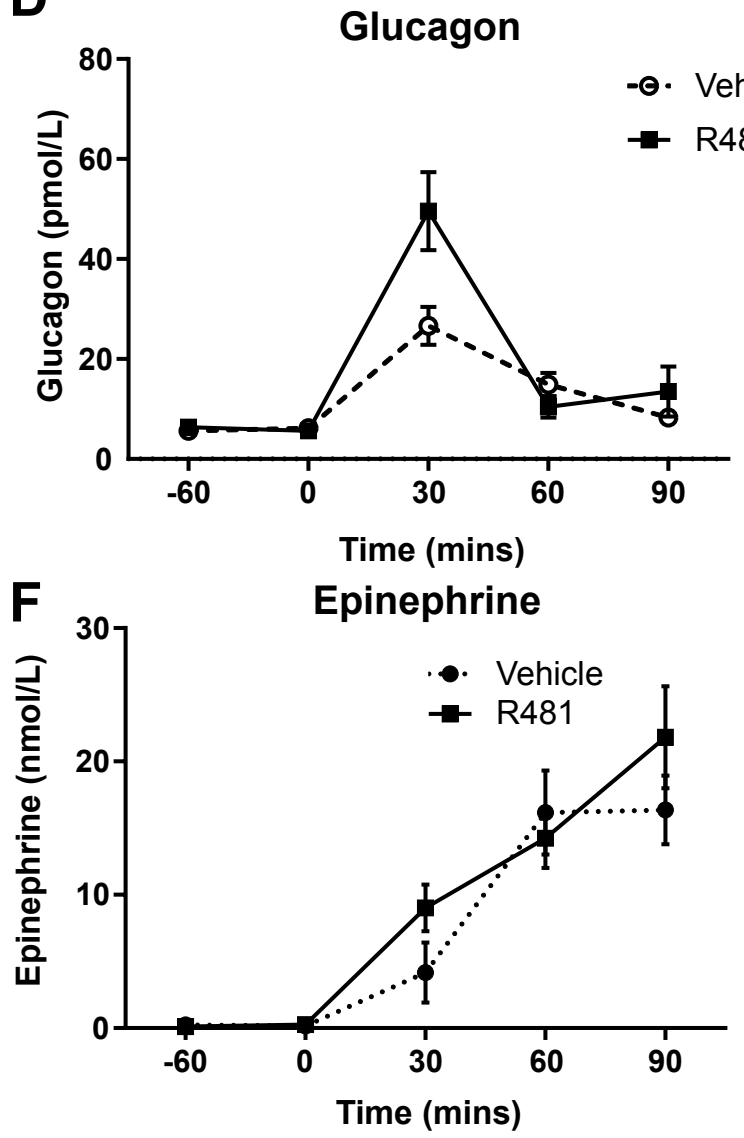

C

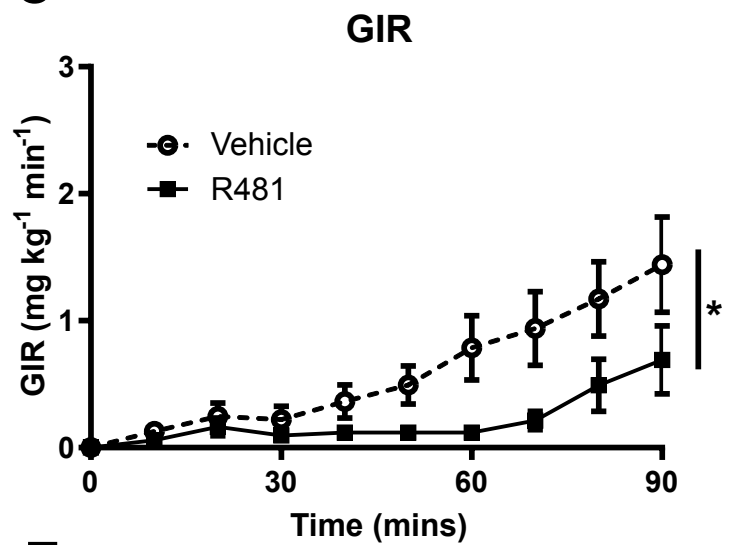

E
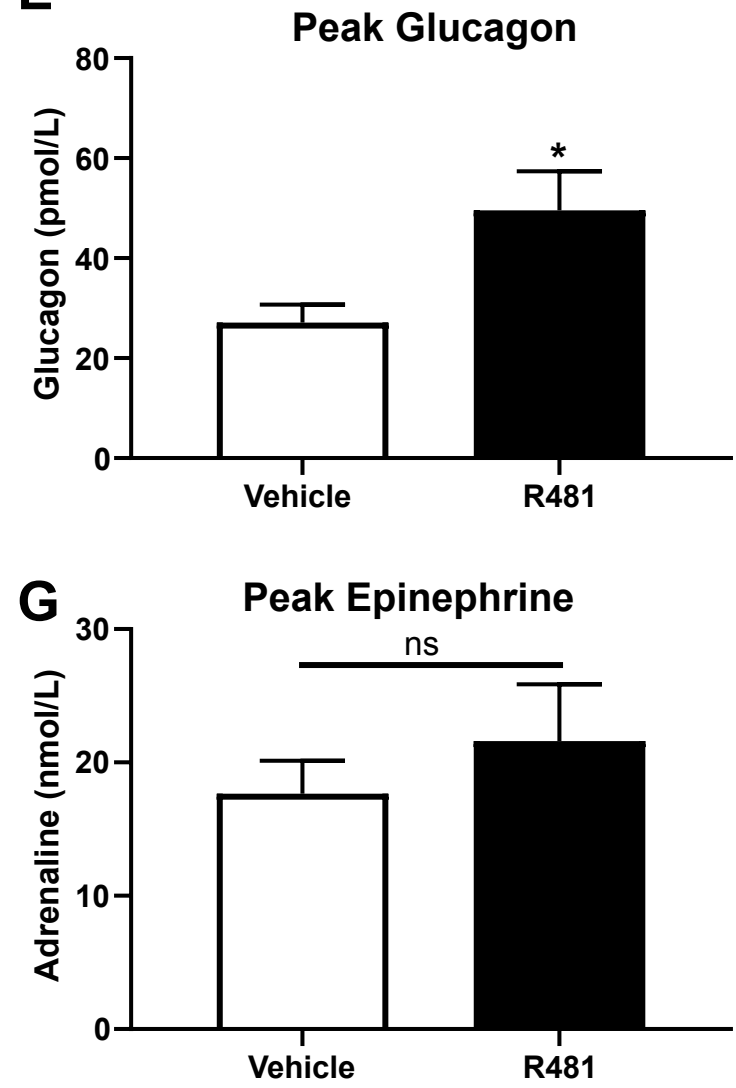

Figure 4. R481 delays exogenous glucose requirements during hyperinsulinemic-hypoglycemic clamp by augmenting glucagon levels during hypoglycemia

Hyperinsulinemic-hypoglycemic clamps performed in male Sprague-Dawley rats. A. Study design. Animals were fasted for 16 hrs. R481 (20 mg kg-1; i.p.) or vehicle (HPMC/Tween-80; i.p.) were administered 60 minutes before the start of the clamp. Blood glucose was measured every 10 minutes and samples collected for plasma analysis at 30 minute intervals. B. Blood glucose profiles before and during clamp (Vehicle $\mathrm{n}=10 ; \mathrm{R} 481 \mathrm{n}=8)$. C. Glucose infusion rates (GIR; $\mathrm{mg} \mathrm{kg}^{-1}$ $\mathrm{min}^{-1}$ ) during the clamp using a $20 \%$ dextrose solution. ${ }^{*} \mathrm{P}($ drug $)<0.05,{ }^{* * *} \mathrm{P}($ time $)<0.05$, ${ }^{*} \mathrm{P}$ (interaction $)<0.05$; two-way ANOVA with repeated measures. D. Plasma glucagon profile with peak shown in $E$, measured by ELISA (Vehicle $n=9$; $R 491 \mathrm{n}=9$; ${ }^{*} \mathrm{P}<0.05$, unpaired t-test). $\mathbf{F}$. Plasma epinephrine profile with peak shown in $\mathbf{G}$, meaured by ELISA (Vehicle $\mathrm{n}=8$; R481 n=8; ns, not significant). 


\section{$\alpha$ TC1-9 OCR}

Change in OCR

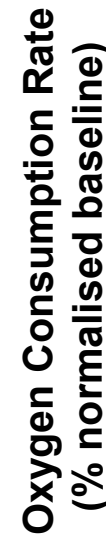
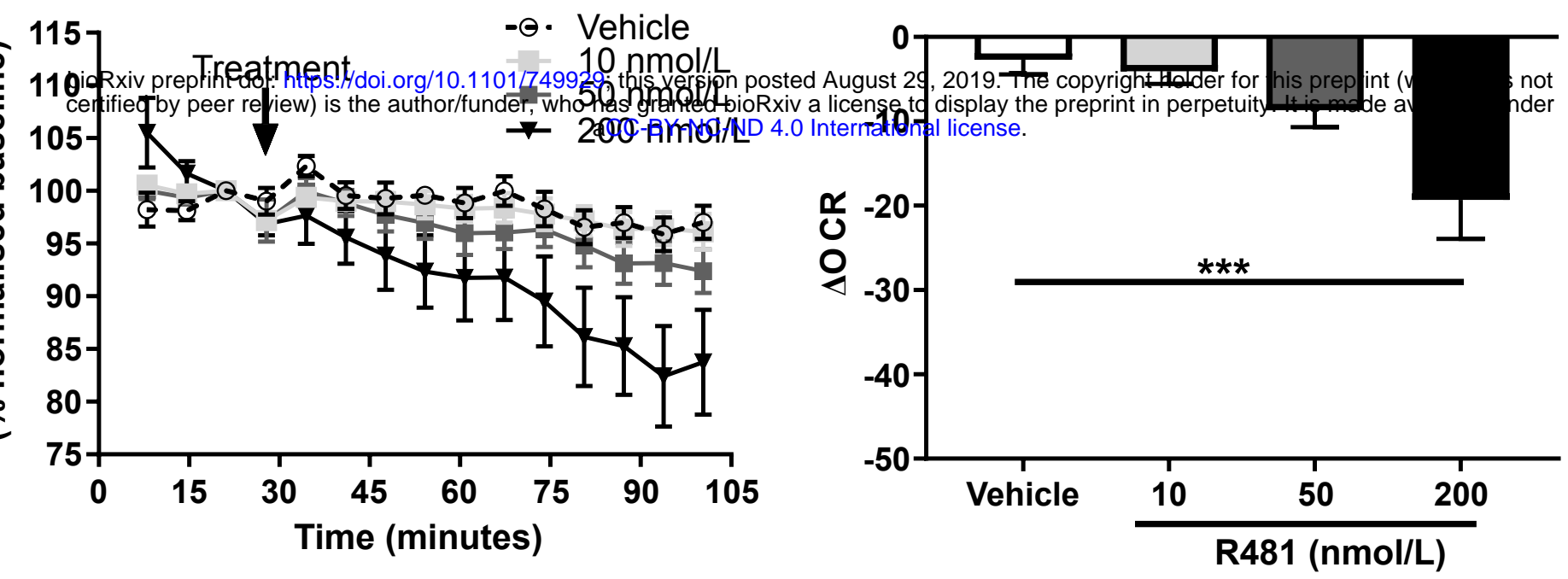

Supplemental Figure 1. R481 reduces mitochondrial oxygen consumption in alpha cell line $\alpha$ TC1-9. A. Extracellular flux analysis measured by Seahorse analyzer $(n=6-10)$. B. Change in Oxygen Consumption Rate (OCR) approximately 80 minutes post injection (denoted by arrow; $\mathrm{n}=6-10 ; * * * \mathrm{P}<0.005$ ). Mean and SEM. 


\section{Whole Brain [4hrs post-dose]}

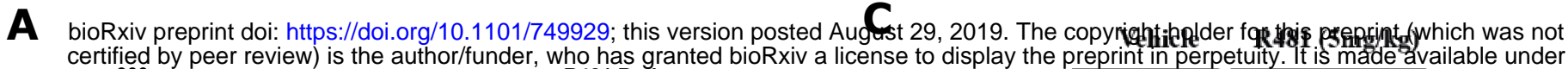

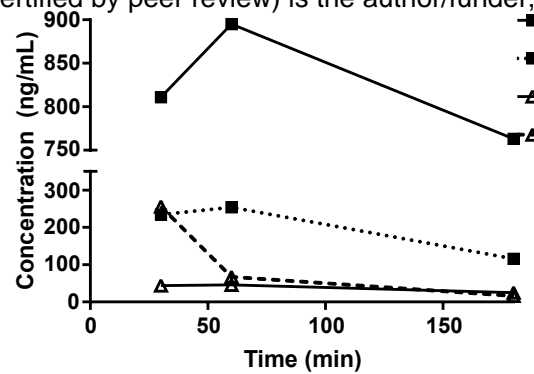

B

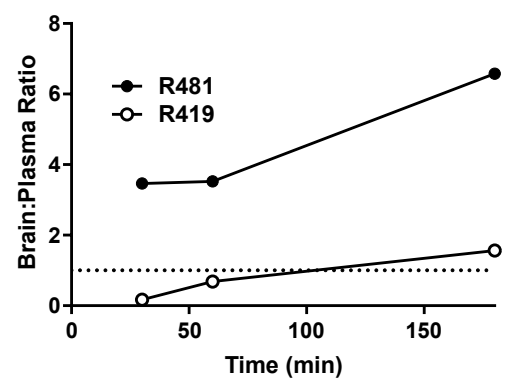

- R481 Plasma

$\triangle$ R419 Brain

R419 Plasma

P-ACC
K
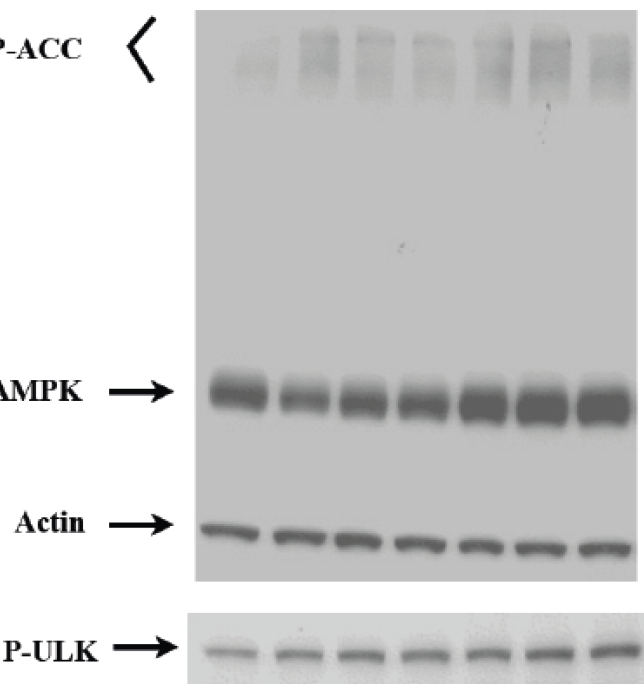

Supplementary Figure 2. R481 accumulates in brain and activates AMPK in Balb/c mice. A. Brain and plasma levels of R481 and R419 measured from Balb/c mice following dosing ( $1 \mathrm{mg} / \mathrm{kg}$; i.v. bolus). B. Brain:plasma ratios of R481 and R419. C. Representative Western blots of pT172 AMPK, pS79 ACC and pS555 ULK1 4 hours after oral dosing in mice (R481; 5 mg/kg; p.o.). Data provided by Rigel Pharmaceuticals, Inc. 
bioRxiv preprint doi: https://doi.org/10.1101/749929; this version posted August 29, 2019. The copyright holder for this preprint (which was not

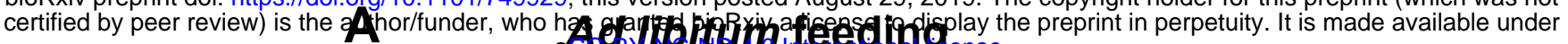

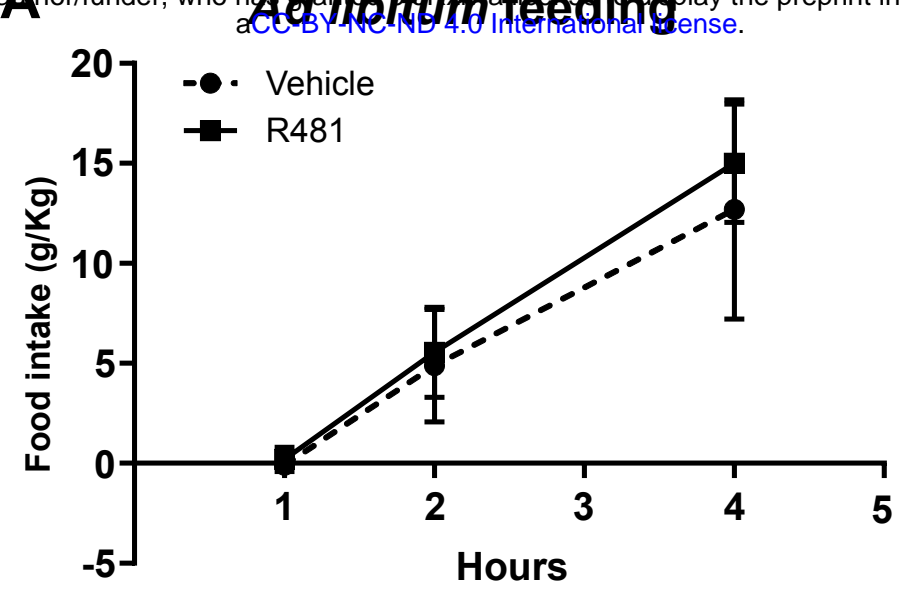

B

Hypoglycemia-induced feeding

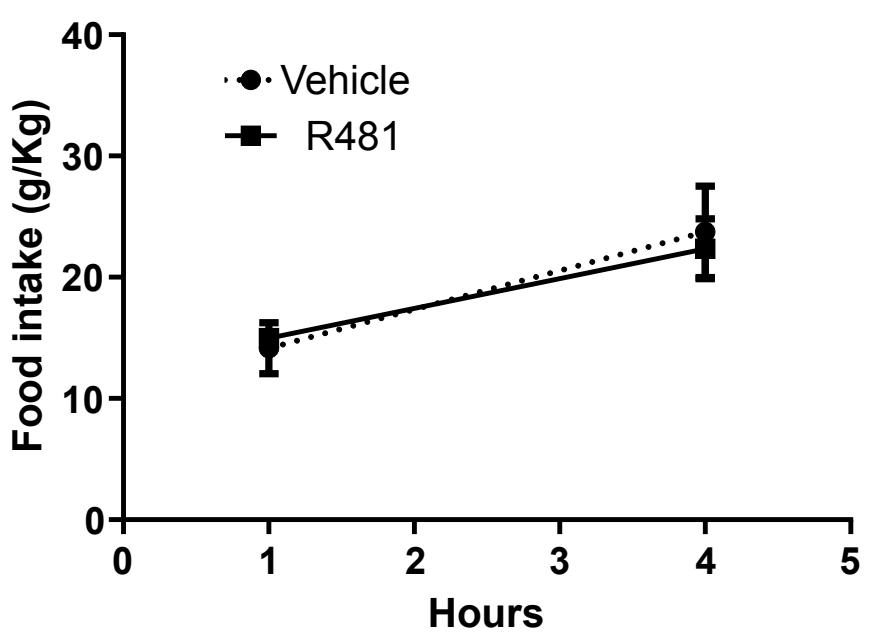

Fast-induced feeding

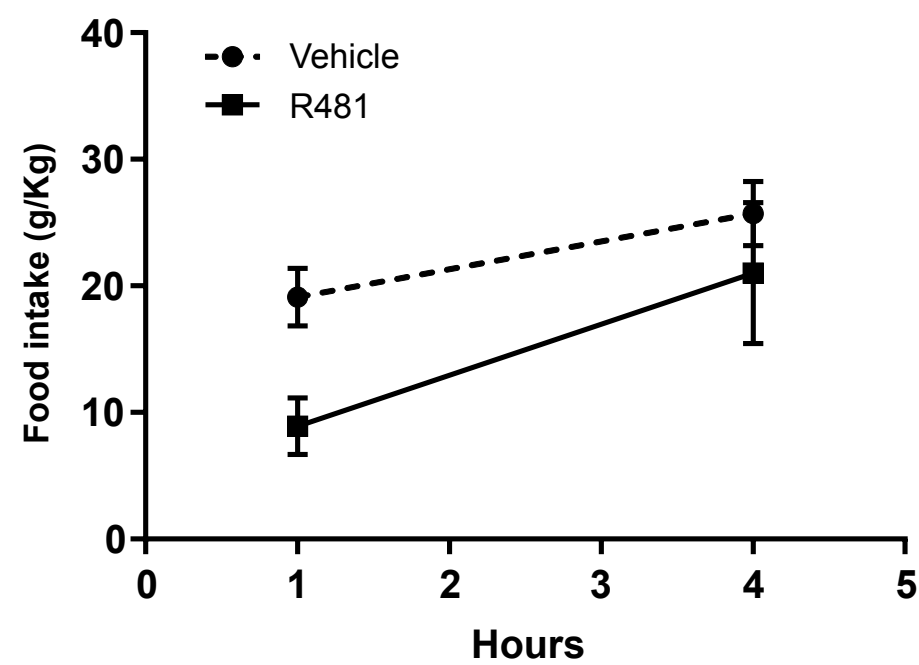

Supplemental Figure 3. R481 had no effect on feeding ad libitum or in response to fasting or insulin treatment.

A. R481 (20 mg kg-1; i.p.) was administered at the start of the dark-phase and food intake measured 1-4 hours following injection (Vehicle $\mathrm{n}=4 ; \mathrm{R} 481 \mathrm{n}=4)$. B. R481 (5 mg kg-1; orally) was administered one hour prior to insulin injection $\left(0.75 \mathrm{U} \mathrm{kg}^{-1}\right.$; i.p.), food re-introduced after 60 minutes and intake measured 1 and 4 hours later (Vehicle $n=5 ; R 481 \mathrm{n}=5$ ). C. Rats were administered $R 481$ (20 mg kg-1; i.p.) following 16 hour fast and food introduced immediately following injection and measured 1 and 4 hours later (Vehicle $n=9 ; R 481 n=9$ ); Two-way ANOVA with repeated measures. Data presented as mean \pm SEM. 